\title{
Effects of a Two-Year Home-Based Exercise Training Program on Oxidized LDL and HDL Lipids in Coronary Artery Disease Patients with and without Type-2 Diabetes
}

\author{
Sanna Tiainen ${ }^{1,2, *} \mathbb{\infty}$, Antti Kiviniemi ${ }^{3}(\mathbb{D})$, Arto Hautala ${ }^{4}\left(\mathbb{D}\right.$, Heikki Huikuri $^{3}$, Olavi Ukkola $^{3}(\mathbb{D}$, \\ Kari Tokola ${ }^{5}$, Mikko Tulppo ${ }^{3}$ and Tommi Vasankari ${ }^{5}$ (i) \\ 1 Sports Institute of Finland, 19100 Vierumäki, Finland \\ 2 Department of Health and Exercise and Paavo Nurmi Center, University of Turku, 20540 Turku, Finland \\ 3 Research of Internal Medicine, Medical Research Center Oulu, Oulu University, Hospital and University of \\ Oulu, 90220 Oulu, Finland; Antti.M.Kiviniemi@oulu.fi (A.K.); heikki.huikuri@oulu.fi (H.H.); \\ olavi.ukkola@oulu.fi (O.U.); mikko.tulppo@oulu.fi (M.T.) \\ 4 Cardiovascular Research Group, Division of Cardiology, Oulu University Hospital, University of Oulu, \\ 90220 Oulu, Finland; arto.hautala@hur.fi \\ 5 The UKK Institute for Health Promotion Research, 33500 Tampere, Finland; kari.tokola@uta.fi (K.T.); \\ tommi.vasankari@uta.fi (T.V.) \\ * Correspondence: sanna.tiainen@vierumaki.fi
}

Received: 19 August 2018; Accepted: 12 October 2018; Published: 16 October 2018

\begin{abstract}
We investigated the effect of two-year home-based exercise training program on oxidized low-density lipoprotein LDL (ox-LDL) and high-density lipoprotein HDL (ox-HDL) lipids in patients with coronary artery disease (CAD), both with and without type-2 diabetes (T2D). Analysis of lipoprotein-oxidized lipids was based on the determination of baseline conjugated dienes in lipoprotein lipids. In order to study the effect of an exercise load on ox-LDL and ox-HDL lipids patients in both CAD and CAD + T2D intervention, groups were divided in three based on exercise load (high, medium, and low). During the two-year home-based exercise training program, the study showed that only higher training volume resulted in a decreased concentration of ox-LDL, while the two groups with lower training volumes showed no change. This result indicates that the training load needs to be sufficiently high in order to decrease the concentration of atherogenic ox-LDL lipids in patients with CAD and CAD + T2D. Interestingly, the concentration of ox-HDL did not change in any of the subgroups. This could indicate that the lipid peroxide-transporting capacity of HDL, suggested by results from exercise training studies in healthy adults, may not function similarly in CAD patients with or without T2D. Moreover, the lipid-lowering medication used may have had an influence on these results.
\end{abstract}

Keywords: exercise; oxidized LDL lipids; oxidized HDL lipids; serum lipids

\section{Introduction}

Cardiovascular diseases (CVD) are a major global cause of premature death, chronic disability [1], and ischaemic heart disease, including coronary artery disease (CAD), which is the leading cause of death from CVD [2]. Major risk factors for cardiovascular diseases include hypertension, smoking, diabetes, diet factors, being overweight, obesity, physical inactivity, and elevated levels of serum total or LDL cholesterol, as well as low levels of HDL cholesterol [3-6]. Oxidized lipids in circulating LDL are also shown to be strongly associated with coronary atherosclerosis, arterial dysfunctions, 
and mortality [7-10]. In addition, several studies have demonstrated the relationship between oxidized LDL lipids (ox-LDL lipids) and CVD risk factors, such as hypertension [11], smoking [12], and obesity [13]. However, only a few studies have investigated the role of oxidized HDL lipids (ox-HDL lipids) in atherosclerosis and CVDs. One study observed that ox-HDL lipids are implicated in the risk of atherosclerosis, although in an opposite manner to that of ox-LDL lipids [14].

Physical activity and exercise training are key elements in the management of CAD $[15,16]$ and type-2 diabetes (T2D) [17], while aerobic exercise has also shown to increase the likelihood of successful body-weight maintenance [18-20]. Both poor cardiorespiratory and muscular fitness, and low levels of leisure-time physical activity are also associated with higher concentrations of ox-LDL lipids [21]. However, both good cardiorespiratory fitness and muscular fitness seem to protect overweight subjects from an atherogenic lipid profile, such as a high level of ox-LDL lipids [22]. Earlier studies have also reported that acute exercise may induce an acute increase of ox-HDL lipids, suggesting that acute aerobic exercise may enhance the lipid peroxide-transporting capacity of HDL [23].

Recently, we have found that the concentration of ox-HDL lipids increased during a six-month aerobic exercise intervention, which suggests that aerobic exercise intervention may enhance the lipid peroxide-transporting capacity of HDL [24]. In the present study, we investigated the effect of a two-year home-based exercise training on ox-LDL and ox-HDL lipids in coronary artery disease patients with and without type-2 diabetes.

\section{Materials and Methods}

\subsection{Subjects and Study Protocol}

The ARTEMIS (innovation to reduce cardiovascular complications of diabetes at the intersection) study was initiated to assess the significance of autonomic, electrical, coronary angiographic, and metabolic markers in predicting cardiovascular events among CAD patients with (CAD + T2D patients) and without T2D (CAD patients) [25]. In addition to this, the study aimed to assess the prognostic significance of these markers in predicting CV events among CAD patients with and without T2D. CAD patients with and without T2D were recruited (1:1 matched in terms of age, sex, history of recent ( $<3$ months) myocardial infarction and type of coronary intervention after angiography) from patients undergoing coronary angiography in the department of cardiology at Oulu University Hospital. As a substudy, both patients with and without T2D were chosen to undergo a two-year controlled exercise training trial with home monitoring to assess the effects of exercise training on risk profiles. Between August 2007 and March 2011, there were approximately 539 CAD patients with T2D and 507 CAD patients without T2D in the ARTEMIS database (Figure 1). Of those patients, 644 were deemed inappropriate to be included in the study due their failing to meet the selection criteria, while 111 were not willing to participate in the study. That resulted in a total of 291 patients who were eligible and willing to participate in the study. These 291 patients were divided into 2 groups consisting of an exercise training group $(n=146)$ and a control group $(n=145)$. The patients in each group were matched 1:1 in terms of gender and the presence of T2D. The 135 patients of the exercise group who took part in follow-up measurements were included in the analyses of cardiovascular risk factors according to the intention-to-treat principle. This study focused on levels of ox-LDL and ox-HDL lipids at the main research design (intervention vs. control), and during further analysis (results presented by exercise load and by waist circumference). The study was performed according to the Declaration of Helsinki. The local committee of research ethics of the Northern Ostrobothnia Hospital District approved the study protocol. All of the selected patients gave their written consent. 


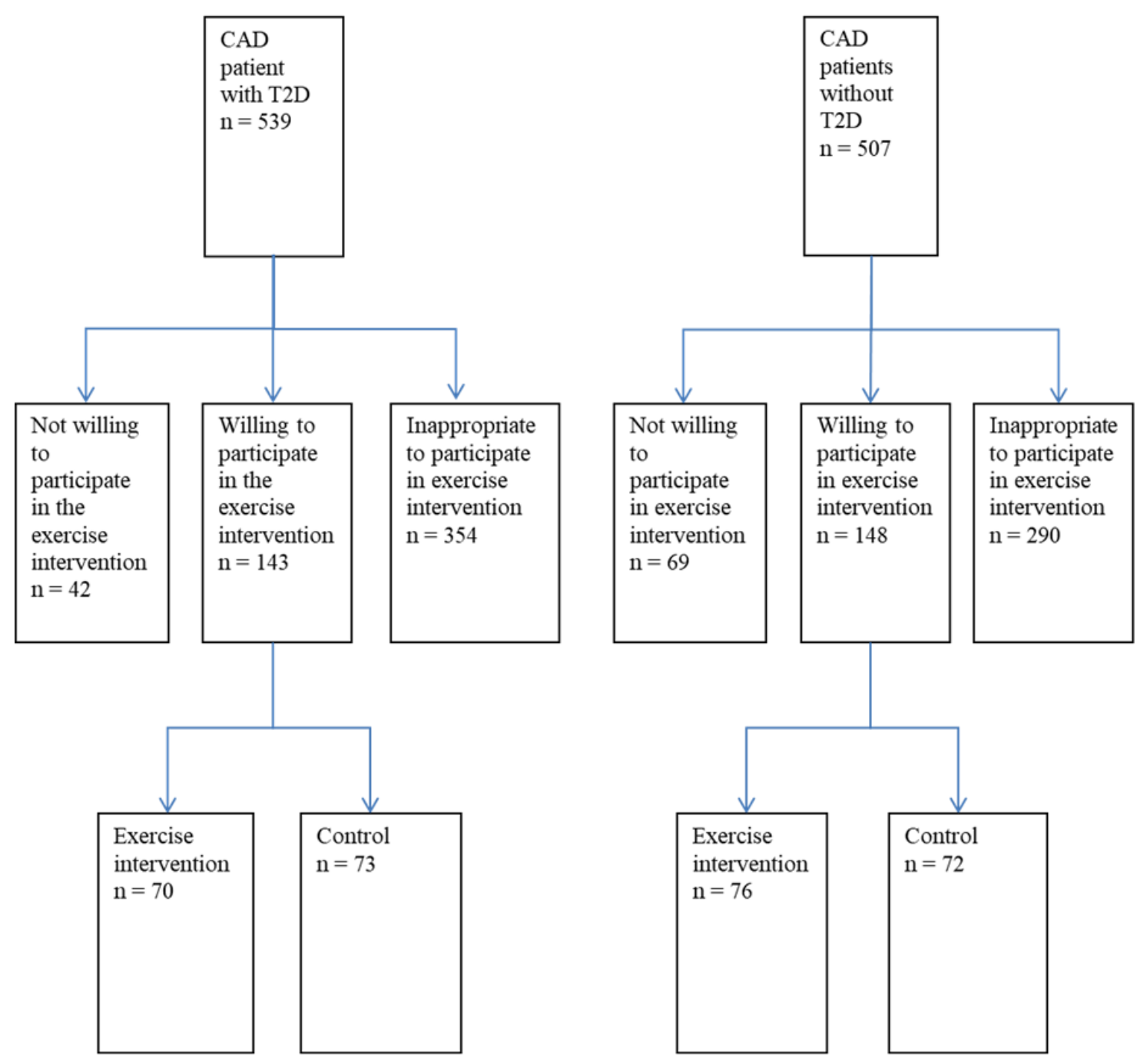

Figure 1. Patient selection protocol from the ARTEMIS database. Note: CAD, coronary artery disease; T2D, type-2 diabetes.

\subsection{Exercise Training Intervention}

Patients in the exercise training group were given a training program for the study, along with a diary to record their training data (training mode, duration, and mean heart rate (Polar F1; Polar Electro Oy, Kempele, Finland). During the first 3 months of the study, the training program consisted of a weekly level of three $30 \mathrm{~min}$ endurance-based sessions (at a 50-60\% intensity level) and a $30 \mathrm{~min}$ strength-based session. For the final 6 months, the weekly program consisted of five $40 \mathrm{~min}$ endurance-based sessions and one $30 \mathrm{~min}$ strength-based session. Of the five endurance-based sessions, 2 were at a $50-60 \%$ intensity level, 2 at a $60-70 \%$ intensity level, and 1 was interval training at a $70-80 \%$ intensity level. Patients in the control group did not receive any individually tailored exercise program.

\subsection{Measurement of Leisure-Time Physical Activity (LTPA)}

Patients were given a baseline health questionnaire about the frequency of their habitual LTPA. Based on this information, 4 physical activity groups were formed by modifying a scale originally developed by Saltin and Grimby [26].

(1) No LTPA (very little physical activity or light housework).

(2) Random LTPA (random light physical activity like walking or cycling).

(3) Moderate LTPA (Engages in physical activity at moderate level 2 to 3 times per week). 
(4) Moderate or high LTPA (Engages in physical activity at moderate or high level more than 3 times per week).

The Saltin-Grimby Physical Activity-Level Scale has shown good validity [27] and has been shown to be related to both CV risk factors [27,28] and CV outcomes [29].

\subsection{Exercise-Capacity Measurement}

To assess exercise capacity, the patients were all asked to perform an incremental symptom-limited maximal exercise test on a bicycle ergometer (Monark Ergomedic 839 E; Monark Exercise AB, Vansbro, Sweden). The test was performed with a starting work rate level of $30 \mathrm{~W}$. After that, the level was increased every $60 \mathrm{~s}$ by $15 \mathrm{~W}$ for male patients and $10 \mathrm{~W}$ for female patients. The test ended at voluntary exhaustion or ST depression $0.2 \mathrm{mV}$ in electrocardiogram (ECG) (CAM-14; GE Healthcare, Freiburg, Germany). The maximal workload of the patients was calculated as the mean workload during the last minute of the test. Based on this maximal workload, maximal exercise capacity was then calculated.

\subsection{Exercise Training Load}

The weekly training load for the intervention group was calculated as the mean training impulse (TRIMP) using the following formula: TRIMP $=\mathrm{ABC}$, in which $\mathrm{A}$ is the exercise time in minutes, $\mathrm{B}$ is the heart rate (proportioned to the heart rate reserve), and $\mathrm{C}$ is $\mathrm{e}^{1.92 \mathrm{~B}}$ for men and $\mathrm{e}^{1.67 \mathrm{~B}}$ for women [30]. TRIMP was used to divide the participants into 3 groups based on the exercise load (high, medium, and low training load).

\subsection{Measurements of CV Risk Factors}

Weight, waist, and hip measurements were taken to assess body composition. After a $10 \mathrm{~min}$ resting period, blood pressure was measured with the patients in a supine position. Blood samples were obtained after a $12 \mathrm{~h}$ overnight fast for analysis of blood lipids using standardized methods.

\subsection{Determination of Oxidized Lipoprotein Lipids}

Examination of lipoprotein oxidized lipids was based on a determination of the baseline level of conjugated dienes in the lipoprotein lipids and it has been reported earlier in detail [31]. Appearance of conjugated dienes has traditionally been utilized as the index of oxidation in vitro and ex vivo examinations of LDL oxidation. First, serum LDL is isolated by precipitation with buffered heparin [31]. Isolation of the HDL part from serum samples is done using phosphotungstic acid precipitation [32]. The isolation methodology is validated for this purpose and it does not influence the level of oxidized lipids [31]. Lipids are removed from isolated lipoproteins by chloroform-methanol (2:1), dried under nitrogen, and thereafter redissolved in cyclohexane. The amount of peroxidized lipids in the lipoprotein lipids is evaluated by spectrophotometry as the amount of diene conjugation (AT $234 \mathrm{~nm}$ ). Studies investigating assay validation have eliminated interference by nonspecific materials, and have demonstrated that diene conjugation is a measure of oxidative LDL modification that is found in all LDL lipid classes. Along with the particular absorption spectra at $234 \mathrm{~nm}$, the existence of conjugated dienes has been confirmed by NMR studies [7]. The coefficient of variation for within-examination accuracy for the assurance of oxidized lipoprotein lipids was $4.4 \%$, and the coefficient of variation for the between-examination accuracy was $4.5 \%$.

\subsection{Statistical Analysis}

First, the effect of the 2-year home-based exercise training intervention on ox-LDL and ox-HDL lipids was analyzed comparing intervention and control patients, both in coronary artery disease patients with and without type-2 diabetes. In order to study the effect of exercise load on ox-LDL and ox-HDL lipids, patients in both the CAD and CAD + T2D intervention groups were combined 
and the subjects were divided into 3 groups based on exercise load (high, medium, and low training load). Further, both in the CAD and in the CAD + T2D group, we divided the intervention group into 3 subgroups based on waist measurements. The men were divided into subgroups with waist measurements of $<94,94-102$, and $>102 \mathrm{~cm}$. The women were divided into subgroups with waist measurements of $<80,80-88$, and $>88 \mathrm{~cm}$. Descriptive group characteristics are shown as means with standard deviation (SD) or number of units (N) with percentages. Analysis of covariance (Ancova) adjusted for age, sex, and baseline value of outcome variable was used to estimate the effect of intervention and exercise on change in lipids. A $p$-value lower than 0.05 was considered statistically significant. All statistical analyses were conducted using IBM SPSS Statistics for Windows (Version 24.0: IBM Corp., Armonk, NY, USA).

\section{Results}

The baseline means of the plasma lipids between the CAD + T2D intervention and control group, and between the CAD intervention and the control group, did not differ in any of the measures before the study (Table 1), nor were there any changes during the intervention between the CAD + T2D intervention and control group, and between the CAD intervention and the control group.

Table 1. Clinical characteristics of the participants.

\begin{tabular}{|c|c|c|c|c|}
\hline Measures & $\begin{array}{l}\text { CAD and CAD + T2D } \\
\text { Control Baseline } \\
(n=126-132)\end{array}$ & $\begin{array}{l}\text { CAD and CAD + } \\
\text { T2D Control } 2 \text { Years } \\
(n=128-132)\end{array}$ & $\begin{array}{c}\text { CAD and CAD + T2D } \\
\text { Exercise Intervention } \\
\text { Baseline }(n=84-93)\end{array}$ & $\begin{array}{l}\text { CAD and CAD + T2D } \\
\text { Exercise Intervention } \\
2 \text { Years }(n=85-93)\end{array}$ \\
\hline Age (years) & $61.2(6.1)$ & $63.2(6.1)$ & $62.0(5.2)$ & $64.0(5.2)$ \\
\hline Gender, male (\%) & $98(74 \%)$ & $98(74 \%)$ & $72(77 \%)$ & $72(77 \%)$ \\
\hline Diabetics, n (\%) & $64(50 \%)$ & $64(50 \%)$ & $43(46 \%)$ & $43(46 \%)$ \\
\hline Smoking, n (\%) & $14(10 \%)$ & $18(13 \%)$ & $6(7 \%)$ & $8(9 \%)$ \\
\hline Height $(\mathrm{cm})$ & $172(8)$ & $172(8)$ & $171(9)$ & $171(9)$ \\
\hline Weight (kg) & $83.6(15.2)$ & $84.0(15.4)$ & $82.1(13.6)$ & $81.4(14.0)$ \\
\hline $\mathrm{BMI}\left(\mathrm{kg} / \mathrm{m}^{2}\right)$ & $28.3(3.9)$ & $28.4(4.1)$ & $28.1(3.7)$ & $27.8(3.7)$ \\
\hline Waist $(\mathrm{cm})$ & $98.8(12.9)$ & $100.5(13.6)$ & $97.5(11.2)$ & $96.6(11.1)$ \\
\hline Systolic RR (mmHg) & $145(23)$ & $145(26)$ & $145(23)$ & $144(21)$ \\
\hline Diastolic RR (mmHg) & $82(11)$ & $80(13)$ & $83(12)$ & $80(10)$ \\
\hline $\mathrm{HbA} 1 \mathrm{c}, \%$ & $6.5(1.2)$ & $6.2(0.9)$ & $6.2(0.7)$ & $6.0(0.7)$ \\
\hline $\begin{array}{l}\text { Plasma glucose } \\
(\mathrm{mmol} / \mathrm{L})\end{array}$ & $6.5(1.7)$ & $6.5(1.6)$ & $6.0(1.1)$ & $6.2(1.2)$ \\
\hline $\begin{array}{l}\text { Total cholesterol } \\
\quad(\mathrm{mmol} / \mathrm{L})\end{array}$ & $4.0(0.9)$ & $4.0(0.8)$ & $4.0(0.8)$ & $4.1(0.8)$ \\
\hline $\begin{array}{l}\text { Triglycerides } \\
\text { (mmol/L) }\end{array}$ & $1.4(0.9)$ & $1.5(0.8)$ & $1.5(0.8)$ & $1.5(0.7)$ \\
\hline Ox-HDL $(\mu \mathrm{mol} / \mathrm{L})$ & $29.9(4.6)$ & $32.3(4.9)$ & $30.2(5.1)$ & $32.9(6.2)$ \\
\hline $\begin{array}{l}\text { HDL cholesterol } \\
(\mathrm{mmol} / \mathrm{L})\end{array}$ & $1.3(0.3)$ & $1.3(0.3)$ & $1.2(0.3)$ & $1.3(0.3)$ \\
\hline Ox-HDL/HDL-cholesterol & $24.6(6.5)$ & $26.3(7.1)$ & $25.7(7.3)$ & $27.2(8.9)$ \\
\hline Ox-LDL $(\mu \mathrm{mol} / \mathrm{L})$ & $41.8(9.3)$ & $41.2(9.2)$ & $43.1(8.2)$ & $42.1(8.4)$ \\
\hline $\begin{array}{l}\text { LDL cholesterol } \\
(\mathrm{mmol} / \mathrm{L}))\end{array}$ & $2.3(0.8)$ & $2.3(0.7)$ & $2.3(0.7)$ & $2.4(0.8)$ \\
\hline Ox-LDL/LDL-cholesterol & $19.9(7.7)$ & $19.9(7.6)$ & $20.0(7.4)$ & $19.4(7.2)$ \\
\hline $\begin{array}{l}\text { Lipid-lowering } \\
\text { medication, n }(\%)\end{array}$ & $119(90 \%)$ & $118(90 \%)$ & $84(90 \%)$ & $86(93 \%)$ \\
\hline
\end{tabular}

Abbreviations: CAD: coronary artery disease; T2D: type 2 diabetes; BMI: body mass index; HDL: high density lipoprotein; LDL: low density lipoprotein; RR: blood pressure; HbA1c: glycated hemoglobin; Ox-HDL: oxidized HDL lipids; Ox-LDL: oxidized LDL lipids. The values denote mean (standard deviation) or number (\%). Numbers of the participants differ somewhat between the measures.

\subsection{Ox-LDL and Ox-HDL in Training Load Subgroups}

In order to study the effect of training volume on ox-LDL and ox-HDL lipid changes, subjects in the intervention group (CAD and CAD + T2D patients combined) were divided into three subgroups based on the training load. The concentration of ox-LDL lipids in the subgroup with the high training load $(41.3 \pm 8.6 \mu \mathrm{mol} / \mathrm{L}$ at baseline and $39.4 \pm 7.4 \mu \mathrm{mol} / \mathrm{L}$ at 2 years $)$ decreased compared to the subgroup with a low training load $(42.5 \pm 9.3 \mu \mathrm{mol} / \mathrm{L}$ at baseline and $43.5 \pm 10.4 \mu \mathrm{mol} / \mathrm{L}$ at 2 years $)$ 
(the change, $p=0.016$, Figure 2). No significant differences were seen between the medium training-load $(44.9 \pm 7.1 \mu \mathrm{mol} / \mathrm{L}$ at baseline and $43.5 \pm 7.6 \mu \mathrm{mol} / \mathrm{L}$ at 2 years $)$ and the low training-load subgroups in ox-LDL lipids $(p=0.093)$. In ox-HDL lipids, no significant differences were seen between the high training-load $(28.8 \pm 5.2 \mu \mathrm{mol} / \mathrm{L}$ at baseline and $32.0 \pm 5.6 \mu \mathrm{mol} / \mathrm{L}$ at 2 years $)$ and the low training-load subgroups $(31.2 \pm 5.9 \mu \mathrm{mol} / \mathrm{L}$ at baseline and $33.4 \pm 7.3 \mu \mathrm{mol} / \mathrm{L}$ at 2 years $)(p=0.243)$ or between the medium training-load $(30.6 \pm 4.4 \mu \mathrm{mol} / \mathrm{L}$ at baseline and $33.3 \pm 6.2 \mu \mathrm{mol} / \mathrm{L}$ at 2 years) and the low training-load subgroups $(p=0.473)$ (Figure 3).

\section{Change of ox-LDL ( $\mu \mathrm{mol} / \mathrm{L})$}

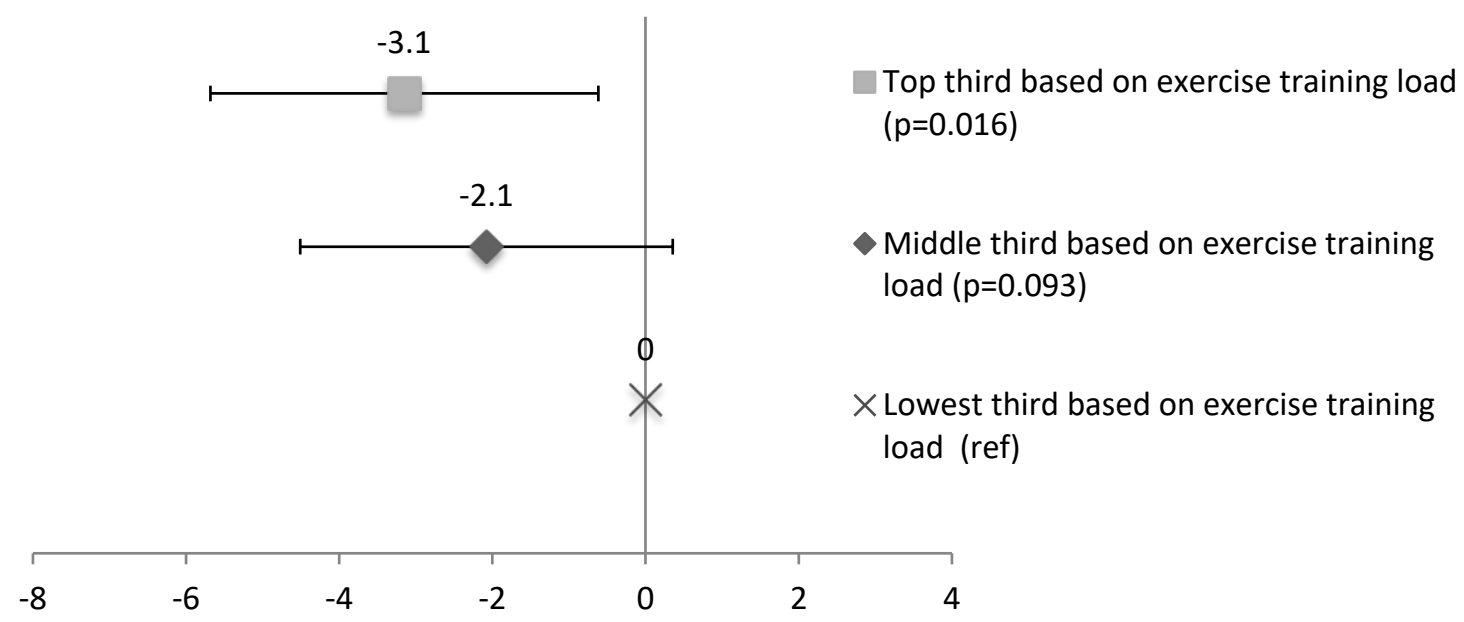

Figure 2. The change of oxidized LDL lipids in the intervention group (CAD and CAD + T2D) based on the exercise training load of the subgroups. Mean and confidence intervals, CI.

\section{Change of ox-HDL ( $\mu \mathrm{mol} / \mathrm{L})$}

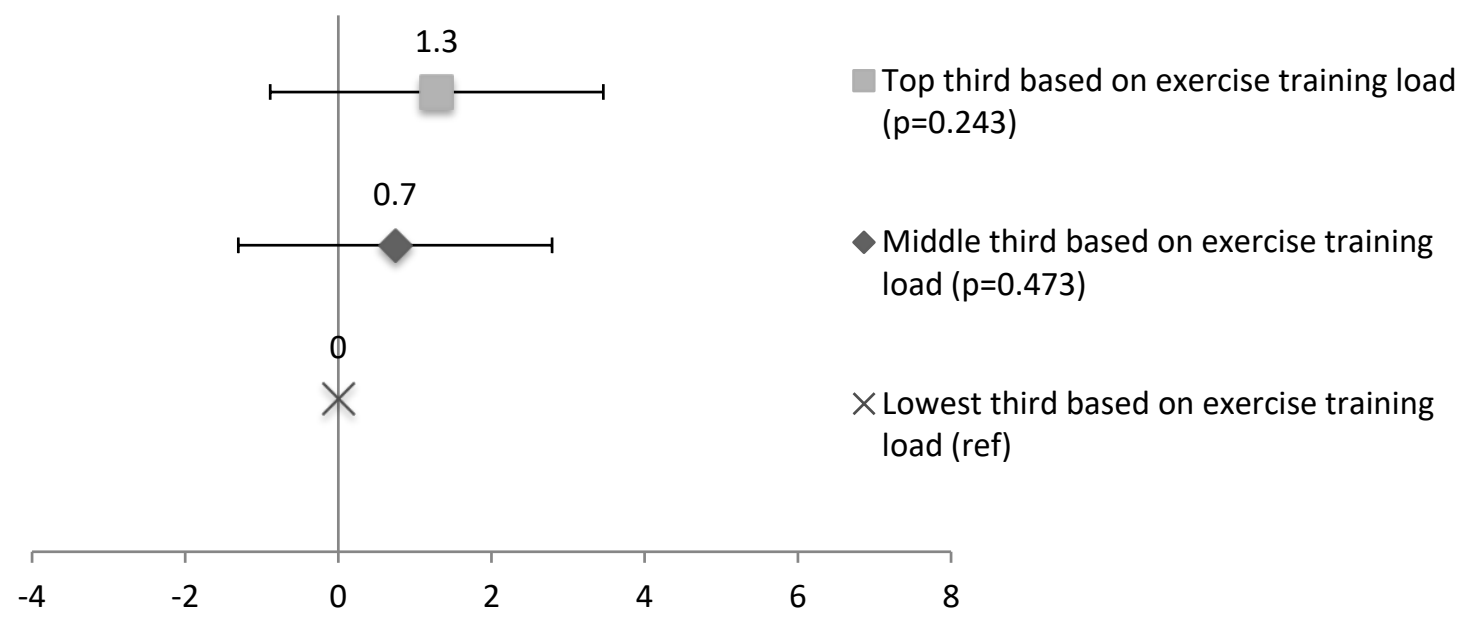

Figure 3. The change of oxidized HDL lipids in the intervention group (CAD and CAD + T2D) based on the exercise training load of the subgroups. Mean and CI.

\section{2. $O x$-LDL and $O x$-HDL Lipids in the Intervention Waist Circumference Subgroups}

In CAD patients, the concentration of ox-LDL lipids decreased during intervention in the subgroups with the widest baseline waist circumference ( $>102 \mathrm{men} / 88$ women: $45.9 \pm 10.4 \mu \mathrm{mol} / \mathrm{L}$ at baseline and $43.1 \pm 9.4 \mu \mathrm{mol} / \mathrm{L}$ at 2 years, $\mathrm{n}=19)$ compared to the CAD control group $(40.4 \pm 9.7 \mu \mathrm{mol} / \mathrm{L}$ at baseline and $40.2 \pm 10.0 \mu \mathrm{mol} / \mathrm{L}$ at 2 years; $\mathrm{n}=65)(p=0.035)$, while no significant changes were seen between other $\mathrm{CAD}$ waist-circumference subgroups (waist circumference 
94-102 men/80-88 women: $42.4 \pm 7.5 \mu \mathrm{mol} / \mathrm{L}$ at baseline and $42.0 \pm 8.6 \mu \mathrm{mol} / \mathrm{L}$ at 2 years, $\mathrm{n}=30$; and waist circumference $<94 \mathrm{men} /<80$ women: $40.9 \pm 9.4 \mu \mathrm{mol} / \mathrm{L}$ at baseline and $41.5 \pm 10.9 \mu \mathrm{mol} / \mathrm{L}$ at 2 years, $\mathrm{n}=19$ ) and controls (Figure 4 ). No changes were observed in ox-HDL lipids between CAD waist-circumference subgroups (waist circumference $>102$ men/88 women: $28.5 \pm 4.8 \mu \mathrm{mol} / \mathrm{L}$ at baseline and $32.2 \pm 5.7 \mu \mathrm{mol} / \mathrm{L}$ at 2 years, $\mathrm{n}=19$; waist circumference 94-102 men/80-88 women: $32.3 \pm 3.6 \mu \mathrm{mol} / \mathrm{L}$ at baseline and $34.9 \pm 4.2 \mu \mathrm{mol} / \mathrm{L}$ at 2 years, $\mathrm{n}=30$; and waist circumference $<94$ men / <80 women: $33.1 \pm 5.7 \mu \mathrm{mol} / \mathrm{L}$ at baseline and $35.6 \pm 5.9 \mu \mathrm{mol} / \mathrm{L}$ at 2 years $\mathrm{n}=19)$ and controls $(31.5 \pm 4.1 \mu \mathrm{mol} / \mathrm{L}$ at baseline and $33.7 \pm 4.5 \mu \mathrm{mol} / \mathrm{L}$ at 2 years; $\mathrm{n}=65)$ (Figure 5), nor were there any changes seen in ox-LDL or ox-HDL lipids between CAD + T2D waist-circumference subgroups.

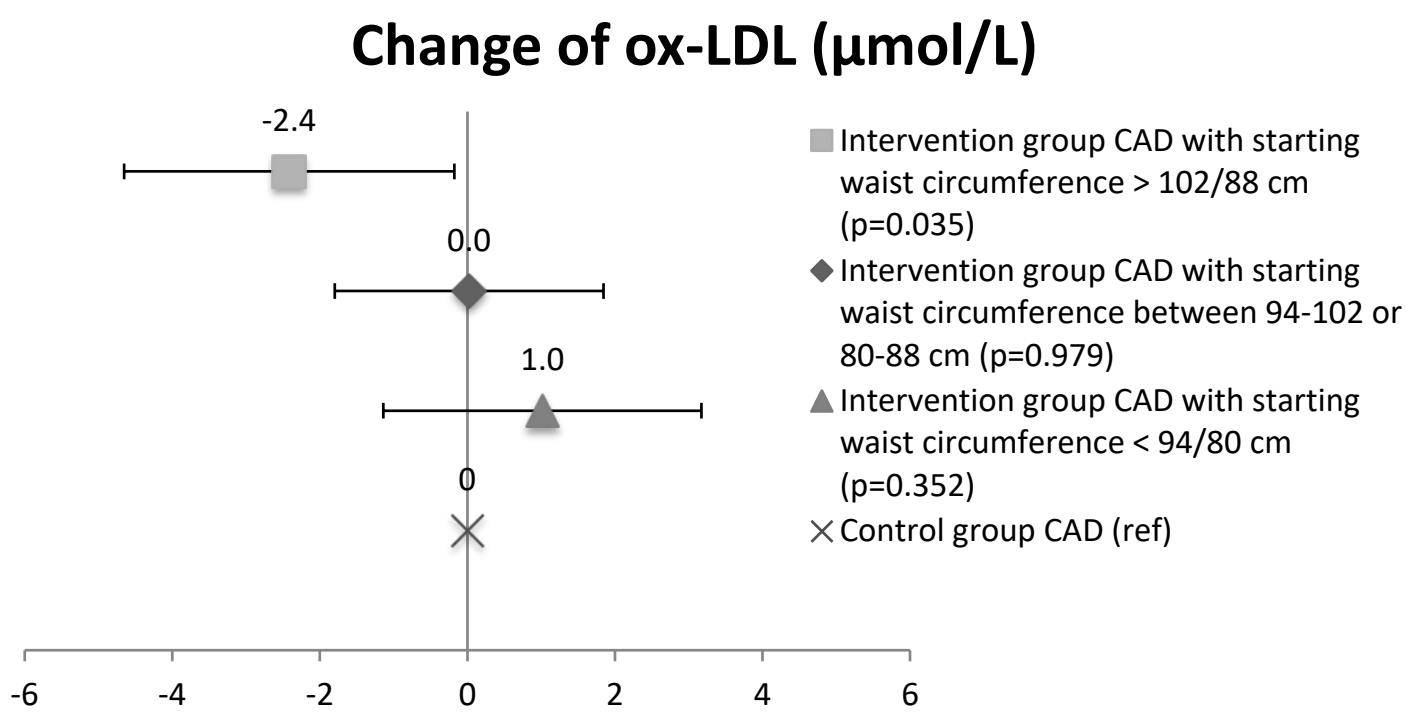

Figure 4. Change of oxidized LDL lipids in CAD waist-circumference subgroups. Mean and CI.

\section{Change of ox-HDL ( $\mu \mathrm{mol} / \mathrm{L})$}

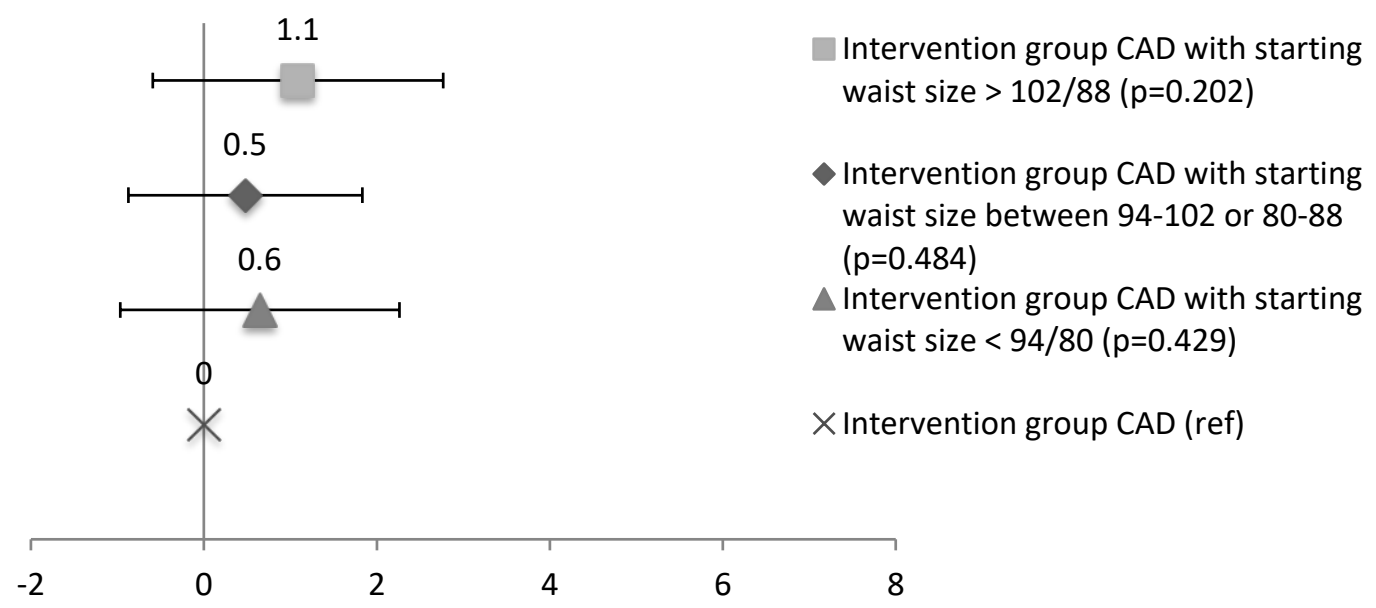

Figure 5. Change of oxidized HDL lipids in CAD waist-circumference subgroups. Mean and CI.

\section{Discussion}

The concentration of ox-LDL was decreased in the subgroup with the highest training load during the two-year home-based exercise training in patients with CAD and CAD + T2D. The present study showed that only the higher training volume resulted in a decreased concentration of ox-LDL, while the two groups with lower training volumes did not result in decreased concentration of ox-LDL. This result indicates that training load needs to be sufficiently demanding in order to decrease the 
concentration of atherogenic ox-LDL lipids patients with CAD and CAD + T2D. Our study is in line with earlier studies, where exercise training intervention decreased concentration of ox-LDL in subjects without CAD [33]. Interestingly, the concentration of ox-HDL was not changed even in the subgroup that performed the greatest volume of exercise. Therefore, although a six-month aerobic exercise intervention was shown to increase the concentration of ox-HDL lipids in healthy menopausal women [24], this was not the case in patients with CAD and CAD + T2D patients during this two-year home-based exercise training program. This could indicate that the lipid peroxide-transporting capacity of HDL, suggested by results from an exercise training study in healthy adults, may not similarly function in CAD patients with and without T2D. Moreover, the lipid-lowering medication used may have had an influence on these results, since it has been presented that statins may decrease the concentration of native LDL cholesterol, while it does not influence the concentration of oxidatively modified LDL particles [34]. However, nearly all participants used statins because all of them had CAD.

In this two-year controlled exercise training, we investigated the effects of home-based exercise training on oxidized LDL and HDL lipids in coronary artery disease patients with and without type-2 diabetes. When comparing the CAD and CAD + T2D intervention and control groups as a whole, we found no significant changes in the concentration of ox-HDL lipids. However, earlier studies have reported that a high volume of physical activity and exercise training are known to be valuable nonpharmacological means of managing CAD and T2D [15-17]. The exercise training intervention that resulted in a 19\% increase in maximal oxygen uptake also decreased the concentration of ox-LDL in healthy adults [33]. Similarly, good aerobic fitness is associated with a low concentration of ox-LDL lipids [21]. However, this two-year home-based exercise training was not intensive enough to induce changes in serum lipids [25], and ox-LDL and ox-HDL lipids.

The CAD patients with the highest waist circumference at baseline reported significant changes in ox-LDL concentration. This finding is supported by an earlier study, where both good cardiorespiratory fitness and muscular fitness seemed to protect overweight subjects from atherogenic lipid profile, such as a high level of ox-LDL lipids [22]. Further, successful maintenance of weight loss has been reported to be accompanied by reduced ox-LDL lipids in obese men, which could indicate a decreased risk of atherosclerosis [13]. However, no statistically significant differences were seen between the waist-circumference subgroups in CAD + T2D patients. This could mean that the altered glucose metabolism in T2D patients might have influenced the ox-LDL lipid metabolism.

Earlier studies have reported that intense exercise, such as vigorous running, may induce an acute increase of ox-HDL [23]. Several studies have also indicated that acute and prolonged physical exercise decreases the concentration of ox-LDL lipids [33,35-37]. To our knowledge, no earlier studies have been published where the effects of exercise training on oxidized HDL and LDL lipids have been studied in CAD patients. Although the current study did not report significant changes in ox-HDL and ox-LDL lipids in all patients in the intervention group, high-volume training was accompanied with a decreased concentration of ox-LDL lipids. Therefore, physical activity and exercise training is considered to prevent atherogenic changes in lipids and to be an effective nonpharmacological method of preventing atherosclerosis.

\section{Conclusions}

This study shows that a two-year home-based exercise training program with a high volume is accompanied by a decreased concentration of oxidized LDL lipids. The concentration of oxidized HDL lipids did not change during intervention. Our results indicate that a high volume of physical activity and exercise training may protect even CAD patients from both an atherogenic lipid profile and a high level of oxidized LDL lipids; however, a lower volume of training may not have similar influence.

Author Contributions: Data curation, A.K., A.H., H.H., O.U., and M.T.; formal analysis, K.T.; writing一original draft, S.T.; Writing-review and editing, T.V. 
Funding: This research was funded by the Finnish Technology Development Center (TEKES), Helsinki, Finland; the Academy of Finland (\#267435), Helsinki, Finland; the Sigrid Juselius Foundation, Helsinki, Finland; the Paulo Foundation, Espoo, Finland; and the Finnish Foundation for Cardiovascular Research, Helsinki, Finland.

Conflicts of Interest: The authors declare no conflict of interest.

\section{References}

1. Roth, G.A.; Johnson, C.; Abajobir, A.; Abd-Allah, F.; Abera, S.F.; Abyu, G.; Ahmed, M.; Aksut, B.; Alam, T.; Alam, K.; et al. Global, regional, and national burden of cardiovascular diseases for 10 causes, 1990 to 2015. J. Am. Coll. Cardiol. 2017, 70, 1-25. [CrossRef] [PubMed]

2. Wang, H.; Naghavi, M.; Allen, C.; Barber, R.M.; Bhutta, Z.A.; Carter, A.; Casey, D.C.; Charlson, F.J.; Chen, A.Z.; Coates, M.M.; et al. Global, regional, and national life expectancy, all-cause and cause-specific mortality for 249 causes of death, 1980-2015: A systematic analysis for the Global Burden of Disease Study 2015. Lancet 2016, 388, 1459-1544. [CrossRef]

3. Forouzanfar, M.H.; Afshin, A.; Alexander, L.T.; Anderson, H.R.; Bhutta, Z.A.; Biryukov, S.; Brauer, M.; Burnett, R.; Cercy, K.; Charlson, F.J.; et al. Global, regional, and national comparative risk assessment of 79 behavioural, environmental and occupational, and metabolic risks or clusters of risks, 1990-2015: A systematic analysis for the Global Burden of Diseases Study 2015. Lancet 2016, 388, 1659-1724. [CrossRef]

4. Sarwar, N.; Gao, P.; Seshasai, S.R.; Gobin, R.; Kaptoge, S.; Di Angelantio, E.; Ingelsson, E.; Lawlor, D.A.; Selvin, E.; Stampfer, M.; et al. Diabetes mellitus, fasting blood glucose concentration, and risk of vascular disease: A collaborative meta-analysis of 102 prospective studies. Lancet 2010, 375, 2215-2222. [CrossRef] [PubMed]

5. Conroy, R.M.; Pyorala, K.; Fitzgerald, A.P.; Sans, S.; Menotti, A.; De Backer, G.; De Bacquer, D.; Ducimetiére, P.; Jousilahti, P.; Keil, U.; et al. Estimation of ten-year risk of fatal cardiovascular disease in Europe: The SCORE project. Eur. Heart J. 2003, 24, 987-1003. [CrossRef]

6. Expert Panel on Detection Evaluation and Treatment of High Blood Cholesterol in Adults. Executive summary of the third report of the National Cholesterol Education Program (NCEP) Expert Panel on Detection, Evaluation, and Treatment of High Blood Cholesterol in Adults (Adult Treatment Panel III). JAMA 2001, 285, 2486-2497. [CrossRef]

7. Vasankari, T.; Ahotupa, M.; Toikka, J.; Mikkola, J.; Irjala, K.; Pasanen, P.; Neuvonen, K.; Raitakari, O.; Viikari, J. Oxidized LDL and thickness of carotid intima-media are associated with coronary atherosclerosis in middle-aged men: Lower levels of oxidized LDL with statin therapy. Atherosclerosis 2001, 155, 403-412. [CrossRef]

8. Raitakari, O.T.; Toikka, J.O.; Laine, H.; Ahotupa, M.; Iida, H.; Viikari, J.; Hartiala, J.; Knuuti, J. Reduced myocardial flow reserve relates to increased carotid intima-media thickness in healthy young men. Atherosclerosis 2001, 156, 469-475. [CrossRef]

9. Toikka, J.; Niemi, P.; Ahotupa, M.; Niinikoski, H.; Viikari, J.; Rönnemaa, T.; Hartiala, J.; Raitakari, O. Large artery elastic properties in young men: Relationships to serum lipoproteins and oxidized low-density lipoprotein cholesterol. Art. Thromb. Vasc. Biol. 1999, 19, 436-441. [CrossRef]

10. Linna, M.; Ahotupa, M.; Löppönen, M.; Irjala, K.; Vasankari, T. Circulating oxidized LDL lipids, when proportioned to HDL-c, emerged as a risk factor of all-cause mortality in a population-based survival study. Age Ageing 2013, 42, 110-113. [CrossRef] [PubMed]

11. Toikka, J.; Laine, H.; Ahotupa, M.; Haapanen, A.; Viikari, J.; Hartiala, J.J.; Raitakari, O. Increased arterial intima-media thickness and in vivo LDL oxidation in young men with borderline hypertension. Hypertension 2000, 36, 929-933. [CrossRef] [PubMed]

12. Linna, M.; Ahotupa, M.; Irjala, K.; Pöllänen, P.; Huhtaniemi, I.; Mäkinen, J.; Perheentupa, A.; Vasankari, T. Smoking and low serum testosterone associates with high concentration of oxidized LDL. Ann. Med. 2008, 40, 634-640. [CrossRef] [PubMed]

13. Linna, M.; Borg, P.; Kukkonen-Harjula, K.; Fogelholm, M.; Ahotupa, M.; Vasankari, T. Weight reduction lowers and consecutive weight maintenance preserves reduced risk for atheroclerosis indicated by lower levels of oxidized LDL. Int. J. Obes. 2007, 31, 245-253. [CrossRef] [PubMed] 
14. Kresanov, P.; Ahotupa, M.; Vasankari, T.; Kaikkonen, J.; Kähönen, M.; Lehtimäki, T.; Viikari, J.; Raitakari, O. The associations of oxidized high-density lipoprotein lipids with risk factors for atherosclerosis. The Cardiovascular Risk in Young Finns Study. Free Radic. Biol. Med. 2013, 65, 1284-1290. [CrossRef] [PubMed]

15. Balady, G.J.; Williams, M.A.; Ades, P.A.; Bittner, V.; Comoss, P.; Foody, J.M.; Franklin, B.; Sanderson, B.; Southard, D.; American Heart Association Exercise, Cardiac Rehabilitation, and Prevention Committee, the Council on Clinical Cardiology; et al. Core components of cardiac rehabilitation/secondary prevention programs: 2007 update: A Scientific statement from HT American Heart Association Exercise, Cardiac Rehabilitation, And Prevention Committee, the Council on Clinical Cardiology; the Councils on Cardiovascular Nursing, Epidemiology and Prevention, and Nutrition, Physical Activity, and Metabolism; and American Association of Cardiovascular and Pulmonary Rehabilitation. Circulation 2007, 115, 2675-2682. [CrossRef] [PubMed]

16. Piepoli, M.F.; Corra, U.; Benzwr, W.; Bjarnason-Wehrens, B.; Dendale, P.; Gaita, D.; McGee, H.; Mendes, M.; Niebauer, J.; Zwisler, A.D.; et al. Cardiac Rehabilitation Section of the European Association of Cardiovascular Prevention and Rehabilitation. Secondary prevention through cardiac rehabilitation: From knowledge to implementation. A position paper from Cardiac Rehabilitation Section of the European Association of Cardiovascular Prevention and Rehabilitation. Eur. J. Cardiovasc. Prev. Rehabil. 2010, 17, 1-17. [CrossRef] [PubMed]

17. Buse, J.B.; Ginsberg, H.N.; Bakris, G.L.; Clark, N.G.; Costa, F.; Eckel, R.; Fonseca, V.; Gerstein, H.C.; Grundy, S.; Nesto, R.W.; et al. American Heart Association; American Diabetes Association. Primary prevention of cardiovascular diseases in people with diabetes mellitus: A scientific statement from the American Heart Association and American Diabetes Association. Circulation 2007, 115, 114-126. [CrossRef] [PubMed]

18. Donnelly, J.E.; Hill, J.O.; Jacobsen, D.J.; Potteiger, J.; Sullivan, D.K.; Johnson, S.L.; Heelan, K.; Hise, M.; Fennessey, P.V.; Sonko, B.; et al. Effects of a 16-month randomized controlled exercise trial on body weight and composition in young, overweight men and women: The Midwest Exercise Trial. Arch. Int. Med. 2003, 163, 1343-1350. [CrossRef] [PubMed]

19. Eliakim, A.; Makowski, G.S.; Brasel, J.A.; Cooper, D.M. Adiposity, lipid levels, and brief endurance training in nonobese adolescent males. Int. J. Sports Med. 2000, 21, 327. [CrossRef] [PubMed]

20. Jakicic, J.M.; Marcus, B.H.; Gallgher, K.I.; Napolitano, M.; Lang, W. Effect of exercise duration and intensity on weight loss in overweight, sedentary women. JAMA 2003, 290, 1323-1330. [CrossRef] [PubMed]

21. Kosola, J.; Ahotupa, M.; Kyröläinen, H.; Santtila, M.; Vasankari, T. Both poor cardiorespiratory and weak muscle fitness are related to a high concentration of oxidized low-density lipoprotein lipids. Scand. J. Med. Sci. Sports 2012, 22, 746-755. [CrossRef] [PubMed]

22. Kosola, J.; Ahotupa, M.; Kyröläinen, H.; Santtila, M.; Vasankari, T. Good aerobic and muscular fitness protects overweight men from elevated oxidized LDL. Med. Sci. Sports Exerc. 2012, 44, 563-568. [CrossRef] [PubMed]

23. Ahotupa, M.; Suomela, J.P.; Vuorimaa, T.; Vasankari, T. Lipoprotein-specific transport of circulating lipid peroxides. Ann. Med. 2010, 42, 521-529. [CrossRef] [PubMed]

24. Tiainen, S.; Luoto, R.; Ahotupa, M.; Raitanen, J.; Vasankari, T. 6-mo aerobic exercise intervention enhances the lipid peroxide transport function of HDL. Free Radic. Res. 2016, 50, 1279-1285. [CrossRef] [PubMed]

25. Karjalainen, J.J.; Kiviniemi, A.M.; Hautala, A.J.; Piira, O.-P.; Lepojärvi, E.S.; Perkiömäki, J.S.; Junttila, M.J.; Huikuri, H.V.; Tulppo, M.P. Effects of physical activity and exercise training on cardiovascular risk in coronary artery disease patients with and without type 2 diabetes. Diabetes Care 2015, 38, 1-10. [CrossRef] [PubMed]

26. Saltin, B.; Grimby, G. Physiological analysis of middle-aged and old former athletes. Comparison with still active athletes of the same ages. Circulation 1968, 38, 1104-1115. [CrossRef] [PubMed]

27. Aires, N.; Selmer, R.; Thelle, D. The validity of self-reported leisure time physical activity, and its relationship to serum cholesterol, blood pressure and body mass index. A population based study of 332,182 men and women aged 40-42 years. Eur. J. Epidemiol. 2003, 18, 479-485. [CrossRef] [PubMed]

28. Rödjer, L.; Jonsdottir, I.H.; Rosengren, A.; Björck, L.; Grimby, G.; Thelle, D.S.; Lappas, G.; Börjesson, M. Self-reported leisure time physical activity: A useful assessment tool in everyday health care. BMC Public Health 2012, 12, 693. [CrossRef] [PubMed] 
29. Apullan, F.J.; Bourassa, M.G.; Tardif, J.C.; Fortier, A.; Gayda, M.; Nigam, A. Usefulness of self-reported leisure-time physical activity to predict long-term survival in patients with coronary heart disease. Am. J. Cardiol. 2008, 102, 375-379. [CrossRef] [PubMed]

30. Karjalainen, J.; Kiviniemi, A.; Hautala, A.; Niva, J.; Tulppo, M. Effects of exercise prescription on daily physical activity and maximal exercise capacity in coronary artery disease patients with and without type 2 diabetes. Clin. Physiol. Funct. Imaging 2012, 32, 445-454. [CrossRef] [PubMed]

31. Ahotupa, M.; Marniemi, J.; Lehtimäki, T.; Talvinen, K.; Raitakari, O.T.; Vasankari, T.; Viikari, J.; Luoma, J.; Ylä-Herttuala, S. Baseline diene conjugation in LDL lipids as a direct measure of in vivo LDL oxidation. Clin. Biochem. 1998, 31, 257-261. [CrossRef]

32. Väisänen, S.; Gävert, J.; Julkunen, A.; Voutilainen, E.; Penttilä, I. Contents of apolipoprotein A-I, A-II and B of the human serum fractions for high-density and low-density lipoproteins prepared by common precipitation methods. Scand. J. Clin. Lab. Investig. 1992, 52, 853-862. [CrossRef]

33. Vasankari, T.; Kujala, U.; Vasankari, T.; Ahotupa, M. Reduced oxidized LDL levels after a ten-month exercise training program. Med. Sci. Sports Exerc. 1998, 30, 1496-1501. [CrossRef] [PubMed]

34. Vasankari, T.; Ahotupa, M.; Viikari, J.; Nuotio, I.; Tikkanen, M. Effects of statin therapy on LDL oxidation. Atherosclerosis 2005, 179, 207-209. [CrossRef] [PubMed]

35. Ahotupa, M.; Ruutu, M.; Mäntylä, E. Simple methods of quantifying oxidation products and antioxidant potential of low density lipoproteins. Clin. Biochem. 1996, 29, 139-144. [CrossRef]

36. Vuorimaa, T.; Ahotupa, M.; Irjala, K.; Vasankari, T. Acute prolonged exercise reduces moderately oxidized LDL in healthy men. Int. J. Sports Med. 2005, 26, 420-425. [CrossRef] [PubMed]

37. Välimäki, I.; Vuorimaa, T.; Ahotupa, M.; Kekkonen, R.A.; Korpela, R.; Vasankari, T. Decreased training volume and increased carbohydrate intake increases oxidized LDL levels. Int. J. Sports Med. 2012, 33, $291-296$. [CrossRef] [PubMed]

(C) 2018 by the authors. Licensee MDPI, Basel, Switzerland. This article is an open access article distributed under the terms and conditions of the Creative Commons Attribution (CC BY) license (http://creativecommons.org/licenses/by/4.0/). 